\title{
Planejamento e trabalho das Equipes gestoras de Educação Infantil
}

\author{
Early Childhood Education management Teams' planning and work \\ Planeamiento y trabajo de los Equipos gestores de Educación Infantil \\ Marcela Lemos LeAl ReIS ${ }^{10} 1$ \\ VALDETE CÔCO ${ }^{1}$ \\ ${ }^{1}$ Sistema Municipal de Ensino de Itapemirim, Itapemirim, ES, Brasil. \\ ${ }^{2}$ Universidade Federal do Espírito Santo, Vitória, ES, Brasil.
}

\begin{abstract}
RESUMO
$\mathrm{O}$ artigo tematiza o planejamento com base em dados de pesquisa referentes à configuração do trabalho das equipes gestoras de Educação Infantil nas Secretarias Municipais de Educação. Ancorada em referenciais teóricometodológicos bakhtinianos, a pesquisa, de abordagem qualitativa e caráter exploratório, desenvolveu procedimento de aplicação de questionário às integrantes das equipes gestoras de Educação Infantil, sustentado em uma etapa inicial de observação. A análise dos dados indica que o planejamento educacional se articula diretamente ao trabalho das equipes, associado ao desenvolvimento da primeira etapa da Educação Básica.
\end{abstract}

Palavras-chave: Educação Infantil. Planejamento. Trabalho docente.

\begin{abstract}
This paper approaches planning based on research data that considered the work organization in early childhood education management teams in City Secretariats of Education. This qualitative exploratory research used Bakhtin theoretical and methodological references to develop a questionnaire procedure used with the early childhood education teams' workers, sustained in an initial stage of observation. The data analysis shows that educational planning is joint to the work of the teams in association with the development of the first level of Basic Education.

Keywords: Early childhood education. Planning. Teacher's work.
\end{abstract}

\section{RESUMEN}

El artículo tiene como temática el planeamiento con base en datos de estudios que abordaron la configuración del trabajo de los equipos gestores de Educación Infantil en las Secretarías Municipales de Educación. Sustentadas en referenciales teórico-metodológicos bakhtinianos. La investigación, de abordaje cualitativa y carácter exploratorio, desarrolló procedimientos de aplicación de encuestas a los integrantes de los equipos directivos de Educación Infantil, que celebró una etapa temprana de la primeira observación. El análisis de los datos indica que el planeamiento educacional se articula directamente al trabajo de los equipos, asociado al desarrollo de la primera etapa de la Educación Básica.

Palabras clave: Educación Infantil. Planeamiento. Trabajo docente. 


\section{INTRODUÇÃO}

No contexto da legislação brasileira, a Constituição Federal (BRASIL, 1988) responsabiliza o Estado pela garantia de creche e pré-escola às crianças de zero a cinco anos de idade e a Lei de Diretrizes e Bases da Educação (LDB) de 1996 reconhece a Educação Infantil como primeira etapa da Educação Básica. Essas premissas legais reafirmam o direito de todos à educação, atribuindo aos municípios a responsabilidade pela Educação Infantil, em cooperação técnica e financeira com a União e os Estados. Diante de movimentos legais e de demandas sociais, os municípios, com suas peculiaridades, mobilizaram seus setores para responder às premissas de garantir esse direito, articulando o planejamento e a organização da Educação Infantil em meio às complexidades do atendimento às crianças pequenas. Tal articulação, em muitos municípios, fica sob a responsabilidade de docentes que integram as equipes gestoras de Educação Infantil e atuam nas Secretarias Municipais de Educação (Semes).

Nessa esteira de construção e organização da etapa inicial da Educação Básica, o planejamento de ações no campo da Educação Infantil configura-se como prática primordial. Assim, em âmbito local e nacional, produções e estudos sinalizam a importância de conhecermos os movimentos que circundam o trabalho das equipes gestoras da primeira etapa da Educação Básica (KRAMER, 2001; NUNES, 2005; MELO; PORTO, 2003, KRAMER; NUNES, 2007; CAMPOS, 2012; FERNANDES; GIMENES; CAMPOS, 2013; CÔCO, 2013).

Nesse contexto, a pesquisa de mestrado $^{1}$ concluída em 2015, focalizou os diálogos situados na discussão do atendimento educacional às crianças de zero a cinco anos de idade como responsabilidade mais direta da gestão pública municipal. Balizados pelo referencial teóricometodológico bakhtiniano, adotamos, como opção metodológica, a pesquisa de abordagem qualitativa, de caráter exploratório, com procedimento da aplicação de questionário, sustentado em uma etapa inicial de observação do trabalho das equipes gestoras de Educação Infantil no contexto do Espírito Santo.

$\mathrm{O}$ questionário ${ }^{2}$ foi organizado em oito seções temáticas, com questões abertas e fechadas, possibilitando aos respondentes transitar entre essas seções. Com os resultados da pesquisa, enfatizamos as infinitas possibilidades dialógicas que se constituem quando nos propomos à escuta das diferentes e inúmeras vozes dos

\footnotetext{
${ }^{1}$ Vinculada ao conjunto de produções do Grupo de Pesquisa Formação e Atuação de Educadores (Grufae) com fomento da Coordenação de Aperfeiçoamento de Pessoal de Nível Superior (Capes).

2 Optamos pela disponibilização do questionário online, visando a favorecer o contato com os sujeitos dos distintos municípios do Estado.
}

sujeitos em relação às questões envolvidas em sua atuação como integrantes das equipes gestoras de Educação Infantil nas Semes.

Do total de 78 questionários enviados, correspondentes ao total dos municípios capixabas, 48 sujeitos responderam ao instrumento, abrangendo 39 (50\%) municípios e equipes gestoras de Educação Infantil. Cientes de que estamos ligados como elos na cadeia discursiva (BAKHTIN, 2011), buscamos compreender o alcance da pesquisa para além dos sujeitos diretamente envolvidos, considerando que sua atuação se relaciona com as instituições de Educação Infantil dos municípios, com os docentes e com as crianças. Desse modo, em relação ao total de 1.622 instituições de Educação Infantil $^{3}$ no Espírito Santo, os participantes da pesquisa se relacionam com 1.018 (62,76\%) instituições. Quanto aos 23.761 docentes $^{4}$ atuantes na Educação Infantil, os sujeitos da pesquisa estão diretamente vinculados à prática de 16.829 (71\%) docentes e contribuem para assegurar: a formação continuada; o direito à aprendizagem das crianças; a tomada de decisões concernentes ao planejamento; a execução e a avaliação da Educação Infantil nos municípios do Estado. Acerca do total de 146.486 crianças matriculadas na Educação Infantil, as participantes da pesquisa estão ligadas a 99.542 (67,9\%) crianças de zero a cinco anos de idade que frequentam a primeira etapa da Educação Básica. Essa amplitude nos situa no contexto da Educação Infantil e ressalta nossa responsividade com todo o processo da pesquisa.

Nesse mote, as seções temáticas do instrumento da pesquisa fomentam análises acerca do perfil das integrantes das equipes gestoras, de concepções no campo da Educação Infantil, situando o seu trabalho articulado ao planejamento e à avaliação, bem como à formação. Para as discussões que nos propomos neste artigo, considerando o foco e os limites que temos, buscamos inicialmente abordar as concepções enunciadas pelas participantes sobre criança, Educação Infantil e trabalho das equipes gestoras em diálogo com as Diretrizes Curriculares Nacionais de Educação Infantil (Dcnei), de 2009. Na sequência, discutimos, o planejamento e o trabalho desenvolvidos pelas equipes gestoras diante do desafio do atendimento às crianças de zero a cinco anos de idade, considerando as concepções expressas pelas participantes sobre planejamento, avaliação, oferta e expansão. Destacamos que, embora o diálogo com essas concepções constituam possibilidades de aprofundamento de análises, interessa-nos principalmente, articular tais

\footnotetext{
3 Esses dados quantitativos foram disponibilizados pela Secretaria de Educação do Estado do Espírito Santo (Sedu). (INEP, 2014).

$4 \mathrm{O}$ mesmo docente pode atuar em mais de uma etapa/modalidade de ensino, em mais de um município e em mais de uma rede escolar. (INEP, 2014).
} 
concepções à visibilização do engajamento das equipes gestoras participantes dessa pesquisa e seu esforço em fazer avançar o trabalho coletivo. Por fim, apresentamos as considerações que emergem deste artigo, ressaltando que as próprias equipes gestoras de Educação Infantil se encontram em processo de constituição, e assim como seu trabalho e as demandas por um planejamento educacional que possibilite superar desafios postos ao campo.

\section{CONCEPÇÕES NO CAMPO DA EDUCAÇÃo INFANTIL NAS VOZES DAS INTEGRANTES DAS EQUIPES GESTORAS}

Em interlocução com os enunciados das participantes, ${ }^{5}$ a pesquisa abordou as seguintes concepções: criança, Educação Infantil, práticas pedagógicas, trabalho das equipes de Educação Infantil, planejamento, avaliação, trabalho do professor, formação dos profissionais, gestão das instituições de Educação Infantil, oferta e expansão do atendimento. Consideramos que essas concepções balizam o campo da Educação Infantil, compreendendo que, em “[...] todos os domínios da vida e da criação ideológica, nossa fala contém em abundância palavras de outrem, transmitidas com todos os graus variáveis de precisão e imparcialidade" (BAKHTIN, 1993, p. 139). Assim, nos impulsionamos a este diálogo, considerando as relações imbricadas na composição das concepções de criança, Educação Infantil e trabalho que tensionam o planejamento e o trabalho desenvolvido pelas equipes gestoras de Educação Infantil nas Semes.

Nesse movimento, destacamos a significativa contribuição das Dcneis (BRASIL, 2009), que vêm sendo amplamente discutidas e implementadas em nosso país. Instituídas pela Resolução no 5, de 17 de dezembro de 2009, com caráter mandatório, as Dcneis (BRASIL, 2009) apresentam indicadores importantes para a elaboração das concepções do campo da Educação Infantil, como a concepção de criança, conforme dispõe o art. 4을

[...] é o centro do planejamento curricular, é sujeito histórico e de direitos que, nas interações, relações e práticas cotidianas que vivencia, constrói sua identidade pessoal e coletiva, brinca, imagina, fantasia, deseja, aprende, observa, experimenta, narra, questiona e constrói sentidos sobre a natureza e a sociedade, produzindo cultura (BRASIL, 2009, p. 1).

No art. 5을 da mesma resolução, a concepção de Educação Infantil é assim declarada:

\footnotetext{
${ }^{5}$ Utilizaremos o feminino, pois as 48 participantes (100\%) da pesquisa são do sexo feminino.
}

[...] primeira etapa da educação básica, é oferecida em creches e pré-escolas, as quais se caracterizam como espaços institucionais não domésticos que constituem estabelecimentos educacionais públicos ou privados que educam e cuidam de crianças de zero a cinco anos de idade no período diurno, em jornada integral ou parcial, regulados e supervisionados por órgão competente do sistema de ensino e submetidos a controle social (BRASIL, 2009, p. 1).

Mobilizados, então, pelas indicações do campo da Educação Infantil e pelos enunciados das participantes da pesquisa, elencamos essas e outras concepções balizadoras para o desenvolvimento do trabalho nessa área, as quais, conforme as Dcneis (BRASIL, 2009), estão reiterando a concepção de criança e de Educação Infantil. Nesse movimento, percebemos que essas concepções sinalizam questões que embasam o planejamento e o trabalho que desenvolvem as equipes gestoras de Educação Infantil.

Em uma visão geral das respostas referentes às concepções elencadas, identificamos duas situações diferentes: na primeira, com quatro $(8,33 \%)$ respondentes, não temos especificamente menção às concepções solicitadas - uma (2,08\%) informa que está elaborando e três $(6,25 \%)$ dizem que não podem responder no momento; na segunda, com 41 (85,41\%) respondentes, é possível reunir concepções de criança e Educação Infantil.

Analisando a primeira situação, as enunciações ${ }^{6}$ "Não tenho como responder agora" (P32) 7 e "Estamos em elaboração" $(\mathrm{P} 43)^{8}$ apresentam-nos um destaque para um processo em que as participantes estão elaborando, na atualidade da pesquisa, suas concepções. Os enunciados indicam um modo de nos dizerem que "[...] não podem responder" acerca da concepção de criança e Educação Infantil com uma demarcação enunciativa temporal, ou seja "[...] nesse momento", sinalizando que estão se constituindo nessa dinâmica ativa e na processualidade do próprio trabalho.

Em uma compreensão social e ativa, constatamos, o inacabamento da concepção que vem sendo estruturada e possivelmente certa fragilidade no que se refere ao direcionamento das ações na Rede Municipal de Ensino. Nesse ajuntamento, é possível compreender, com ancoragem bakhtiniana, que

[...] a palavra será sempre o indicador mais sensível de todas as transformações sociais, mesmo daquelas que apenas despontam, que ainda não tomaram

\footnotetext{
${ }_{6}$ As participantes da pesquisa serão codificadas pela letra $\mathrm{P}$, seguida de um número simbólico escolhido aleatoriamente.

7 Declaração expressa em questionário online, respondido voluntariamente. Respostas apuradas em 29 jan. 2015 pela pesquisadora.

8 Declaração expressa em questionário online, respondido voluntariamente. Respostas apuradas em 5 fev. 2015 pela pesquisadora.
} 
forma, que ainda não abriram caminho para sistemas ideológicos estruturados e bem formados. A palavra constitui o meio no qual se produzem lentas acumulações quantitativas de mudanças que ainda não tiveram tempo de adquirir uma nova qualidade ideológica, que ainda não tiveram tempo de engendrar uma forma ideológica nova e acabada. A palavra é capaz de registrar as fases transitórias mais íntimas, mais efêmeras das mudanças sociais (BAKHTIN, 2009, p. 42).

Nessas diferentes vozes sociais entrelaçadas, seguimos dialogando com as concepções enunciadas pelas $41(85,42 \%)$ participantes ao expressarem conceitos que orientam as ações de acompanhar e direcionar o planejamento e o trabalho pedagógico na Educação Infantil.

Considerando as concepções sobre criança, 35 (72,92\%) participantes enunciam que ela é "[...] sujeito de direito e produtora de cultura" (P2,) $)^{9}$, “[...] uma pessoa em permanente desenvolvimento[...]” (P19) ${ }^{10}$. Com esses enunciados, salientamos uma sintonia com as premissas circulantes no campo da Educação Infantil, explicitadas pelas bases legais e reiteradas nas produções acadêmicas e nas bandeiras de lutas dos movimentos sociais ligados à educação das crianças pequenas. Com a pesquisa, assinalamos uma grande cadeia dialógica que reitera uma concepção de criança como sujeito histórico, cultural e com direito à educação.

A concepção de criança como sujeito de direitos também foi registrada na pesquisa realizada por Kramer (2001). Conforme podemos perceber, ao longo dos anos, essa voz que concebe a criança como sujeito de direito vem se fortalecendo e repercutindo no campo da Educação Infantil. Outras seis participantes (12,50\%) visibilizam, com destaque bem semelhante, as concepções de criança e Educação Infantil balizadas nas Dcneis (BRASIL, 2009). O enunciado que segue reúne as semelhanças a que nos referimos: "Criança - sujeito de direitos, competente, capaz, centro do planejamento curricular, e Educação Infantil - primeira etapa da Educação Básica, cuja finalidade é o desenvolvimento integral da criança; é oferecido em creches e pré-escolas e nesses espaços se cuida e educa crianças [...]" (P37) ${ }^{11}$.

Foi possível perceber que, além de se inserirem no campo dialógico legal, acadêmico e dos movimentos sociais, as participantes têm seu auditório social e nele redizem as concepções de criança e Educação Infantil que escutam.

\footnotetext{
9 Declaração expressa em questionário online, respondido voluntariamente. Respostas apuradas em 9 do dez. 2014 pela pesquisadora.

${ }^{10}$ Declaração expressa em questionário online, respondido voluntariamente. Respostas apuradas em $23 \mathrm{dez} .2014$ pela pesquisadora.

${ }^{11}$ Declaração expressa em questionário online, respondido voluntariamente. Respostas apuradas em 31 jan. 2014 pela pesquisadora.
}

A concepção de criança e Educação Infantil que tenho estão de acordo com as Dcneis, mas consegui aprender mais nos encontros formativos do PróInfância, Pnaic e Educação Integral que frequentei em 2013 e 2014 na Ufes. Esses encontros foram muito bons, porque eu aprendia e repassava para os meus professores na formação continuada mensal do município (P53) ${ }^{12}$.

Assim, os dados nos indicam que muitas ressonâncias conceituais advindas do campo de Educação Infantil dialogam também com eventos formativos dos quais as equipes gestoras participaram, retratam temporalidades diferentes e sinalizam investimentos no acesso à informação e atualização nesse campo. Parece que a participação nesse processo formativo repercute em encontros interativos que promovem a produção de conhecimentos e a formulação dessas concepções que as participantes agora compartilham em seus redizeres.

Nesse sentido, com intenção não de esgotar as análises, mas expandir o diálogo, constatamos que as representações enunciativas, aparentemente silenciadas e embaçadas nas indicações das participantes, reiteram que o campo da Educação Infantil está em constante construção, como tem sido identificado em pesquisas acadêmicas (KRAMER, 2001; KRAMER et al., 2005; KRAMER; NUNES, 2007; CAMPOS, 2012; CÔCO, 2012; FERNANDES; GIMENES; CAMPOS, 2013, VIEIRA; OLIVEIRA, 2013, entre outros).

Concernentemente as $41(85,42 \%)$ respondentes, no que se refere à concepção de trabalho das equipes gestoras de Educação Infantil, observamos, na maioria dos enunciados, uma preocupação das integrantes dessas equipes com a aprendizagem das crianças e compartilhamos que as formas dessa compreensão são diferentes. Ao materializarmos o referencial teórico bakhtiniano em nossa análise, consideramos que “[...] os contextos não estão simplesmente justapostos, como se fossem indiferentes uns aos outros, encontram-se numa situação de interação e de conflito tenso e ininterrupto" (BAKHTIN, 2009, p.111). Nas diferentes formas como são apresentadas as enunciações, observamos alguns movimentos singulares acerca da concepção de trabalho das equipes de Educação Infantil e, certas da inconclusividade dessas análises, optamos por situar dois movimentos.

O primeiro movimento abrange 23 participantes (47,92\%). Seus enunciados evidenciam concepções centralizadas na construção conjunta, no trabalho realizado com responsabilidade, no zelo das equipes, na fiscalização da documentação das instituições de

\footnotetext{
${ }^{12}$ Declaração expressa em questionário online, respondido voluntariamente. Respostas apuradas em 12 fev. 2015 pela pesquisadora.
} 
Educação Infantil e na qualidade da oferta de matrículas para $o$ atendimento das crianças. As crianças perpassam todos esses enunciados, porém não chegam a ocupar centralidade nos processos. Na polifonia das vozes que explicitam as concepções de trabalho das equipes, no que diz respeito ao conjunto de ações que o constituem, uma das participantes diz que: "[...] a equipe tem uma visão de trabalho para o ensino da Educação Infantil como primeira etapa preparatória para o EF" (P4913); outra relaciona a concepção de trabalho com a "[...] equipe unida, avaliando as atividades propostas pelas escolas, os relatos de experiências, as documentações, registros, diários e fiscalizando tudo, para qualidade do ensino aplicado à criança" (P24) ${ }^{14}$. Uma das participantes ainda enfatiza:

Acredito que deveria ter mais membros na equipe da Educação Infantil, para melhorar o acompanhamento dos ensinos dos alunos e das práticas dos professores. Sou sozinha na Educação Infantil e ainda tenho que dar conta de umas turmas de professoras do EF do Pnaic. Um dia é pouco pra fazer o que tenho que fazer e vou fazendo, fazendo até a administração mandar mais alguém (P16) ${ }^{15}$.

Cabe destacar que as participantes consideram que o trabalho das equipes gestoras de Educação Infantil está centralizado na aprendizagem das crianças. Nesse movimento, as concepções de trabalho das equipes estão atreladas à escolarização na Educação Infantil, indicando essa etapa como preparatória para o ensino fundamental. Referente a essa questão, frisamos que as Dcneis (BRASIL, 2009) mencionam que não se devem antecipar conteúdos trabalhados no ensino fundamental, mas garantir, nessa transição, a continuidade do processo de aprendizagem e desenvolvimento das crianças, respeitando suas especificidades. Buscando problematizar a força da presença da escolarização na Educação Infantil, com o dado de que 21 das respondentes $(43,75 \%)$ não frequentaram a Educação Infantil no curso de sua trajetória educativa, concordamos com Côco (2013, p. 193), quando afirma:

[...] nós, que não frequentamos a Educação Infantil, transportamos uma memória da estrutura da escola para o trabalho com as crianças pequenas. Uma compreensão fortalecida pelos processos de formação inicial, geralmente, mais voltados ao trabalho no ensino fundamental. Assim, novas exigências se apresentam

\footnotetext{
${ }^{13}$ Declaração expressa em questionário online, respondido voluntariamente. Respostas apuradas em 6 fev. 2015 pela pesquisadora.

${ }^{14}$ Declaração expressa em questionário online, respondido voluntariamente. Respostas apuradas em 30 dez. 2014 pela pesquisadora.

${ }^{15}$ Declaração expressa em questionário online, respondido voluntariamente. Respostas apuradas no em 23 dez. 2014 pela pesquisadora.
}

ao processo de formação inicial, de envolver as demandas da Educação Infantil. Também ganham relevo as possibilidades de a formação continuada abarcar, na concretude dos cenários educativos da Educação Infantil, seus dilemas, desafios e iniciativas de ação.

Outros desafios ainda são postos para encaminharmos, de modo consistente, a problematização dessa concepção escolarizante na Educação Infantil, entre os quais tratamos das condições de trabalho, com destaque para a sobrecarga de atividades vivenciadas pelas equipes gestoras, conforme já explicitado. $\mathrm{O}$ acúmulo de atividades ganha visibilidade nos enunciados das participantes. Esse acúmulo implica, muitas vezes, distribuir energias em projetos e programas que abarcam outras etapas da Educação Básica. Ainda que as participantes tenham a aprendizagem das crianças como foco das ações das equipes gestoras, a sobrecarga de trabalho pode desfocar as crianças como centro do planejamento curricular, sujeitos históricos e de direitos, produtoras de cultura, com direito a uma educação específica que respeite sua integralidade (BRASIL, 2009). Nesse contexto, compreendemos que os enunciados das participantes reúnem um conjunto de interveniências que impactam diretamente a concepção do trabalho.

A respeito do segundo movimento sobre a concepção do trabalho das equipes gestoras, com 18 participantes $(37,50 \%)$, evidenciamos que elas expressam a concepção de um trabalho que reitera a sua centralidade na criança. Nesse caso, constatamos um empenho na participação social, em uma escuta atenta dos sujeitos que compõem essa coletividade e um trabalho com base nos princípios da gestão democrática:

O trabalho da equipe de Educação Infantil da Semed tem por base os diálogos permanentes com as instituições, a busca constante por atender às demandas apresentadas pela realidade escolar e o alcance das metas estabelecidas a cada ano, visando à aprendizagem das crianças $(\mathrm{P} 08)^{16}$.

[...] gestão democrática, parceria (secretaria e escola), atendimento à legislação vigente com foco na aprendizagem das crianças, parceria com as demais equipes da Seme e parceria na equipe Educação Infantil [nomenclatura da equipe acompanhada de nome do município] (P18) ${ }^{17}$.

Acredito que a equipe precisa estar articulada em relação às concepções de Educação Infantil, estudando os documentos que norteiam o trabalho com crianças dessa faixa etária e discutindo possibilidades de

\footnotetext{
${ }^{16}$ Declaração expressa em questionário online, respondido voluntariamente Respostas apuradas em 19 dez. 2014 pela pesquisadora.

${ }^{17}$ Declaração expressa em questionário online, respondido voluntariamente. Respostas apuradas em 23 dez. 2014 pela pesquisadora.
} 
avanço e acompanhamento das práticas realizadas pelos profissionais que atuam nesse segmento no município (P22) ${ }^{18}$.

$\mathrm{Na}$ continuidade da interlocução, identificamos o fato de, ao registrarem suas concepções de trabalho, as participantes considerarem que o trabalho que desenvolvem na Seme está em interlocução com aquele que implementam nas instituições de Educação Infantil. Quanto ao trabalho das equipes gestoras de Educação Infantil, as respondentes indicam que está situado no diálogo, na escuta coletiva de diferentes sujeitos, com centralidade na educação das crianças.

Desse modo, a concepção de trabalho das equipes gestoras de Educação Infantil se aproxima das concepções de criança e Educação Infantil indicadas nas Dcneis (BRASIL, 2009) e se associa às perspectivas do campo da Educação Infantil. Ressaltamos as indicações de disposição das participantes para escutar atentamente os profissionais e buscar construir uma educação na perspectiva do trabalho coletivo, primando pelas estratégias da gestão democrática. Nesse sentido, destacamos a importância do Plano Nacional de Educação, especialmente em relação à estratégia 19.6, que enfatiza a necessidade de incentivo à participação e à consulta aos profissionais e à comunidade para o desenvolvimento do trabalho e a tomada de decisões nas instituições de educação (BRASIL, 2014).

Indicando a centralidade das crianças nas diferentes concepções de trabalho das equipes gestoras, implicando distintas vias de ação em variados graus de aproximação às instituições e profissionais que atendem às crianças, salientamos que as discussões sobre a precarização do trabalho docente também podem ser remetidas às análises das condições de trabalho desse grupo participante da pesquisa. Nas conquistas e dificuldades no encaminhamento das ações que visam ao desenvolvimento da Educação Infantil, em especial, no âmbito dos municípios e, em particular, no contexto do Espírito Santo, o planejamento emerge recorrentemente como um tema associado ao trabalho das equipes, tópico que desenvolveremos a seguir.

\section{O PLANEJAMENTO E O TRABALHO DAS EQUIPES GESTORAS DE EDUCAÇÃo INFANTIL: DESAFIOS E NUANÇAS}

Em uma mobilização axiológica, no exercício empático de compreensão, em especial no esforço de respondermos aos objetivos deste artigo, que se direcionam ao planejamento e ao trabalho das equipes gestoras,

\footnotetext{
${ }^{18}$ Declaração expressa em questionário online, respondido voluntariamente. Respostas apuradas em 23 dez. 2014 pela pesquisadora.
}

reunimos nossa análise nos indícios dos enunciados que sinalizaram, de maneira diversa, as concepções de planejamento e avaliação. Nesse movimento, dialogamos com os sentidos desses dois termos, considerando o que as participantes apontam em seus enunciados. Atinentes à concepção de planejamento e avaliação, observamos que, diferentemente do movimento relativo às concepções que reunimos com base nos enunciados das 41 participantes $(85,42 \%)$ até o momento, as vozes desta composição consideram o desenvolvimento de seu próprio fazer para enunciarem suas concepções.

As instituições de Educação Infantil recebem destaque por parte de 34 participantes $(70,83 \%)$, ao abordarem o planejamento e a avaliação. Nesse momento, centralizadas nas instituições, elas mencionam as dinâmicas, ou seja, o processo do planejamento e da avaliação, evidenciando a compreensão de que sua atuação está intrinsecamente articulada às instituições. Nessa ocorrência, ressaltamos o compromisso das equipes gestoras de Educação Infantil com o trabalho que desenvolvem, pois sua atenção está voltada para as instituições de Educação Infantil. O compromisso que se apresenta fortemente nesta pesquisa é também identificado na pesquisa realizada por Campos (2012), na qual as equipes são compostas por pessoas comprometidas com a Educação Infantil, com caráter militante, que buscam uma legitimidade para o reconhecimento da primeira etapa da Educação Básica.

Percebemos, portanto, que as integrantes das equipes gestoras de Educação Infantil vivenciam o planejamento e a avaliação e, na simultaneidade de seu trabalho, efetivam suas ações, no intuito de associar suas práticas às indicações das Dcneis (BRASIL, 2009), focalizadas na processualidade e na coletividade. Assim, uma das participantes afirma que "[...] as instituições de educação infantil devem criar procedimentos para acompanhamento do trabalho pedagógico e para avaliação do desenvolvimento das crianças, sem objetivo de seleção, promoção ou classificação" (P9) ${ }^{19}$. Nesse contexto, outra participante realça que "O planejamento é realizado durante os trimestres com o apoio do pedagogo e demais profissionais da escola, priorizando a realidade dos educandos. A avaliação ocorre diariamente, através das observações, é processual e contínua" (P25) ${ }^{20}$.

Respondendo de maneira diferente, outras duas participantes $(4,17 \%)$ afirmam que estão estudando as concepções para inclusão na proposta pedagógica municipal. Dizem também que não podem se posicionar a respeito, por não terem tomado decisões sobre o assunto coletivamente. Esses enunciados evidenciam

\footnotetext{
${ }^{19}$ Declaração expressa em questionário online, respondido voluntariamente. Respostas apuradas em 22 dez. 2014 pela pesquisadora.

${ }^{20}$ Declaração expressa em questionário online, respondido voluntariamente. Respostas apuradas em 23 dez. 2014 pela pesquisadora.
} 
uma predisposição à escuta das vozes dos profissionais da educação e uma busca, na coletividade, de elaboração de um documento específico para a Educação Infantil, considerando a realidade do município, como previsto na LDB (BRASIL, 1996) e nas Dcneis (BRASIL, 2009). Nesse caso, uma delas informa: "As concepções de planejamento e avaliação estão sendo estudadas coletivamente no município, mas, como estamos elaborando a PCM, não posso compartilhar porque ainda não decidimos com todos" (P16) ${ }^{21}$.

Ressaltamos a importância dessa construção formalizada e consensuada ou pelo menos discutida com os envolvidos sobre as concepções que sustentam os encaminhamentos das práticas aqui relativas ao planejamento e à avaliação. Enfatizamos também que essas concepções não dependem de ser escritas ou formalizadas para se constituírem. Elas se fazem presentes e embasam as práticas de planejamento e avaliação ainda que não constem em documentos oficiais.

$\mathrm{Na}$ continuidade, as outras cinco participantes $(10,42 \%)$ efetivam sua centralidade no trabalho que desenvolvem nas equipes gestoras de Educação Infantil, informando que suas concepções de planejamento e avaliação se baseiam nas Dcneis (BRASIL, 2009). Nas minúcias dos enunciados, destacamos que o trabalho com foco na dinâmica das equipes indica a necessidade de um plano, uma agenda elaborada, sistematizada, que possibilite o diálogo com os profissionais das instituições de Educação Infantil. O planejamento e a avaliação são indicados como possibilidades de enxergar as fragilidades para investir em formação ou orientações processuais. Percebemos que há um movimento de preocupação com a instituição de Educação Infantil, visto o reconhecimento de que é lá o lócus da oferta de Educação Infantil. De acordo com as declarações, o trabalho se constitui no coletivo, em interlocução com as instituições de Educação Infantil, focalizando o "[...] planejamento diário e a avaliação permanente do trabalho da equipe, com foco no atendimento das instituições de Educação Infantil" (P6) ${ }^{22}$, com o propósito de "[...] garantir o planejamento e acompanhamento dos profissionais da educação através dos registros e intervenções necessárias ao aperfeiçoamento, partindo do planejamento do setor de Educação Infantil da SEME" (P17) ${ }^{23}$.

Evidenciando mais uma vez o trabalho desenvolvido com a Educação Infantil e também com o ensino fundamental, uma participante detalha:

\footnotetext{
${ }^{21}$ Declaração expressa em questionário online, respondido voluntariamente. Respostas apuradas em 23 dez. 2014 pela pesquisadora.

${ }^{22}$ Declaração expressa em questionário online, respondido voluntariamente. Respostas apuradas em $17 \mathrm{dez} .2014$ pela pesquisadora.

${ }^{23}$ Declaração expressa em questionário online, respondido voluntariamente. Respostas apuradas em 23 dez. 2014 pela pesquisadora.
}

O planejamento do setor é permanente e ele consegue definir nossa rota e nosso objetivo. Às vezes ele muda muito porque estamos envolvidos com muitas atividades do EF também, mas sempre ao pensar e depois ir 'na' realidade das escolas. Avaliamos e (re)planejamos conforme as necessidades das ações. A avaliação que realizamos aqui, no setor de Educação Infantil da Seme, e que também orientamos nas escolas de Educação Infantil é fundamentada na avaliação de base reflexiva, contínua e coletiva. A rotina de funcionamento diário das escolas de Educação Infantil: matutino: $7 \mathrm{~h}$ às $11 \mathrm{~h}$ com aluno, e o professor fica das $7 \mathrm{~h}$ às $12 \mathrm{~h}$, cumprindo quatro horas com o aluno e uma hora de planejamento diário, após o turno, totalizando cinco horas diárias $=25 \mathrm{~h}$ semanais; vespertino: $12 \mathrm{~h} 40 \mathrm{~min}$ às $16 \mathrm{~h} 40 \mathrm{~min}$ com o aluno, e o professor fica das $12 \mathrm{~h} 40 \mathrm{~min}$ às $17 \mathrm{~h} 40 \mathrm{~min}$, cumprindo quatro horas com o aluno e uma hora de planejamento diário após o turno, totalizando cinco horas diárias = $25 \mathrm{~h}$ semanais. O planejamento permanece nas escolas, acontece todos os dias acompanhado pelo pedagogo e, sempre que possível, pelo diretor. Os projetos são decididos e avaliados pela equipe escolar (P29) ${ }^{24}$.

Com esses dados, realçamos o movimento de trabalho das equipes que, ainda que revele fragilidades, assinala e especialmente sugere necessidade de investimentos para o seu fortalecimento na busca por implementar as premissas contidas nas Deneis (BRASIL, 2009).

Ao abordarmos a concepção de oferta e expansão de vagas na Educação Infantil, encontramos consonância nos enunciados quanto ao direito da criança à sua matrícula garantida. As participantes destacam que o Poder Público precisa prever esse atendimento e enfatizam que, além de pensar em oferta e expansão, deve elaborar um planejamento e definir a qualidade, tomando como referência os parâmetros nacionais de qualidade para a Educação Infantil (BRASIL, 2006), ao balizar tais ações.

É recorrente entre as participantes que os municípios vivenciam um momento intenso de planejamento em toda a Rede. Em muitos enunciados, elas atribuem a responsabilidade de oferta e expansão de vagas na Educação Infantil ao Poder Público. Buscamos, então, compreender o que seria o Poder Público para as participantes, uma vez que essa assertiva é reiterada, apontando certo distanciamento das equipes gestoras de Educação Infantil na ação de planejamento da oferta em relação à demanda.

Nesse contexto, constatamos que as participantes, ao se referirem ao Poder Público, expressam que fazem o que podem diante da realidade em que vivem; reconhecem que isso não é suficiente, mas é o que conseguem fazer e

\footnotetext{
${ }^{24}$ Declaração expressa em questionário online, respondido voluntariamente. Respostas apuradas em 23 dez. 2014 pela pesquisadora.
} 
atribuem o não atendimento ao Poder Público, que não dá conta, desvinculando o município dessa responsabilidade, como se esperassem uma solução de um outro órgão público.

Ademais, evidenciam que não participam desse planejamento pontual, pois embora considerem importante essa participação, diante das inúmeras demandas, essa é mais uma ação que se acumula. No movimento cotidiano de trabalho, atendem e tratam a oferta e a expansão não como um planejamento que precisa ser reestruturado a cada previsão de nascimento de uma criança, por exemplo, mas como uma situação de emergência, para "apagar incêndios", como diz uma participante. Atuam conforme a demanda. Uma delas afirma:

[...] a responsabilidade é do Poder Público. Dentro de nossas possibilidades, atendemos e acumulamos mais essa tarefa, mas com necessidade de ampliação e adequação dos espaços que ainda não foram previstos pelo poder público. [...] atendemos a todos que precisam e requerem. É o que conseguimos, porque temos muitas atividades e, para conseguir cumprir tudo, atendemos de forma ordenada. Essa é nossa função. O objetivo é atender muito bem, em todos os âmbitos, atender à criança da melhor maneira possível. A demanda é grande e o Poder Público tem que dar conta $(\mathrm{P} 06)^{25}$.

Assim, conseguimos identificar que a participação das equipes gestoras de Educação Infantil é discreta em relação ao planejamento da oferta, especialmente nas deliberações sobre a expansão do atendimento. Seu trabalho fica mais circunscrito às demandas cotidianas $\mathrm{e}$, reconhecendo a insuficiência da oferta, as participantes buscam alternativas "dentro das possibilidades" dos municípios. As diferentes práticas de oferta e expansão de vagas na Educação Infantil indicam a necessidade de um planejamento, pois, mesmo que compreendamos a importância de uma lista de espera, as listas pouco contribuem para a articulação necessária à expansão e para as ações voltadas ao atendimento das crianças e famílias que permanecem à espera de vagas.

Nesse diálogo potencial com as participantes, encontramo-nos '[....] em 'uma citação' ou 'uma referência' àquilo que disse uma determinada pessoa, ao que 'se diz' ou àquilo que 'todos dizem'” (BAKHTIN, 1993, p.139-140) e ressaltamos a diversidade de concepções sobre o campo da Educação Infantil. Nesse movimento, identificamos que esse campo e os docentes se encontram em um processo contínuo de desenvolvimento, crescendo junto com a expansão do atendimento às crianças.

\footnotetext{
${ }^{25}$ Declaração expressa em questionário online, respondido voluntariamente. Respostas apuradas em 27 dez. 2014 pela pesquisadora.
}

Temos, assim, um cenário que reitera a concepção de criança como sujeito de direitos e produtora de cultura. A reafirmação desse cenário, não sem fragilidades, tensiona as demais concepções, indicando dificuldades que precisamos superar. Assim, é necessário investir em políticas consistentes de formação que requerem ações intencionalmente planejadas no que tange à necessidade de fortalecimento da Educação Infantil, especialmente das equipes gestoras.

Atentos aos dizeres outros das participantes, embora não fosse propósito de nossa pesquisa dialogar com as questões sobre o Plano de Ações Articuladas (PAR), à medida que avançamos nas análises, constatamos que algumas participantes relataram, em seus enunciados, dinâmicas que expressam a percepção das integrantes das equipes gestoras de Educação Infantil acerca da regulamentação, elaboração e implantação do PAR.

Gerenciado pelo Ministério da Educação (MEC), o PAR é um instrumento de planejamento da política nacional brasileira. Realizado com base em um diagnóstico detalhado de toda a rede municipal, o PAR se constitui em quatro dimensões: 1) Gestão Educacional; 2) Formação de Professores e de Profissionais de Serviço e Apoio Escolar; 3) Práticas Pedagógicas e Avaliação; e 4) Infraestrutura Física e Recursos Pedagógicos. Ademais, está diretamente implicado com o Compromisso Todos pela Educação, firmado por adesão. Conforme define o art. 9ํ do Decreto $\mathrm{n}^{\mathrm{O}}$ 6.094, de 24 de abril de 2007, que dispõe sobre a implementação do Plano de Metas Compromisso Todos pela Educação, pela União Federal, em regime de colaboração com Municípios, Distrito Federal e Estados, e a participação das famílias e da comunidade, mediante programas e ações de assistência técnica e financeira, visando à mobilização social pela melhoria da qualidade da Educação Básica, o PAR “[...] é o conjunto articulado de ações, apoiado técnica ou financeiramente pelo Ministério da Educação, que visa o cumprimento das metas do Compromisso e a observância das suas diretrizes" (BRASIL, 2007, p. 4).

Balizando nosso diálogo, o mesmo decreto assim define o Plano de Metas Compromisso Todos pela Educação em seu art. 10.

O Plano de Metas Compromisso Todos pela Educação (Compromisso) é a conjugação dos esforços da União, Estados, Distrito Federal e Municípios, atuando em regime de colaboração, das famílias e da comunidade, em proveito da melhoria da qualidade da educação básica (BRASIL, 2007, p. 1).

Ao analisar os discursos, podemos dizer que as participantes concebem o PAR como "outro plano" 
$(\mathrm{P} 40)^{26}$, demarcando que o planejamento em sua atuação é um instrumento que está presentificado, ou seja, não há somente o planejamento intitulado PAR, e demonstram conhecer outros planos, o que insta uma cultura de organização da atuação docente.

Ao expressarem seus conhecimentos sobre o PAR, as participantes indicam, permeando sua elaboração, que o diferencial desse plano é a construção de um diagnóstico do município. Nessa sequência discursiva, relacionando as vias de acesso com o plano (PAR), percebemos que a hierarquia baliza o acesso e, em tom denunciativo, as participantes elucidam que esse acesso é restrito e vinculado ao Cadastro de Pessoa Física (CPF) do responsável pela Secretaria Municipal de Educação. Também sinalizam que, como integrantes das equipes gestoras de Educação Infantil, embora tenham feito referência a um diagnóstico do município realizado pelo PAR (o que indica um diagnóstico da Educação Infantil do município), informam que não conhecem o conteúdo do planejamento instituído pelo PAR para a primeira etapa. Complementam: "[...] não sei muito dele (PAR) porque não tenho essa responsabilidade" (P40) ${ }^{27}$; "Não tenho muita certeza" (P36) ${ }^{28}$, evidenciando o desconhecimento de mais esse instrumento de planejamento educacional. Aventamos que as equipes gestoras de Educação Infantil não têm pertencimento ao processo de elaboração desse plano e, mais especialmente, não atuam diretamente em articulação com o seu processo de acompanhamento. Algumas participantes mencionam que não têm certeza da dinâmica de sua elaboração e não se sentem responsáveis por esse planejamento e por sua realização.

$\mathrm{Na}$ produção dos dados, com base nos enunciados das participantes, encontramos indícios da metodologia instituída para a elaboração do PAR pelas Semes. Nesse conjunto, constatamos o distanciamento das integrantes das equipes gestoras de Educação Infantil no processo de regulamentação, elaboração e implantação do plano, uma vez que apenas três $(6,25 \%)$ das participantes mencionaram a existência do PAR no município, ao dialogarmos acerca dos documentos locais que orientam o trabalho da educação. Uma delas enfatiza que

[...] ele também é feito pela gerente geral de toda a educação do município, ela faz e depois de fazer, ela dá ciência pelo ofício às outras gerências, mais uma burocracia cumprida. [...] temos uma coordenadora (que muda dependendo de quem ganha a eleição) ela faz esse plano no último ano de cada gestão. No

\footnotetext{
${ }^{26}$ Declaração expressa em questionário online, respondido voluntariamente. Respostas apuradas em 4 fev. 2015 pela pesquisadora.

${ }^{27}$ Declaração expressa em questionário online, respondido voluntariamente. Respostas apuradas em 4 fev. 2015 pela pesquisadora.

${ }^{28}$ Declaração expressa em questionário online, respondido voluntariamente. Respostas apuradas em 29 jan. 2015 pela pesquisadora.
}

último, foi assim: ela nos dividiu. Exemplo, quem estava na Educação Infantil preencheu os campos para informar o diagnóstico da Educação Infantil, quem estava no Ensino Fundamental colocou as informações do Ensino Fundamental e assim foi [...] a coordenadora fatia bem cada campo que eles perguntam e aí os técnicos da Seme colocam o que é da sua competência, ela reúne tudo e deixa tudo pronto no sistema on-line, aí o Governo Federal analisa e envia alguns programas para ajudar o município [...]. Quando trabalhei em outra Secretaria de Educação também era assim, tinha uma coordenadora que recolhia as informações de cada um, juntava e informava no sistema (P36)

Outra pontuação que evidencia a falta de interação das equipes gestoras concernente ao plano se efetiva quando informam que "[...] a gerente geral da educação" (P 36) é a única responsável em dividir as etapas e "[...] os técnicos da Seme colocam o que é da sua competência" $(\mathrm{P} 36)^{30}$, indicando um planejamento isolado em que não há compartilhamento dos desafios e das projeções entre as modalidades. Quanto à coordenadora responsável pelo PAR, descrevem que ela "[...] fatia bem cada campo" (P36) ${ }^{31}$ do PAR, reiterando nossa análise de compartimentação e imprimindo certa familiaridade das integrantes com esse movimento, pois não demonstram nenhum desconforto com essa dinâmica reguladora que, conforme relatam, acontece em outra Seme, ou seja, em outro município em que já atuaram. Assim, enfatizam que veem o PAR como uma ação burocrática e protocolar que precisa ser cumprida, não evidenciando uma compreensão de sua importância no desenvolvimento do trabalho das equipes gestoras de Educação Infantil.

Desse modo, a temática do planejamento apresenta nuanças importantes no desenvolvimento do trabalho das equipes gestoras. Nuanças que retratam tanto os movimentos mais internos às Semes, como as dialogias mais externas, voltadas aos investimentos nas instituições de Educação Infantil. No conjunto, essa é uma temática que, conforme os dados da pesquisa, parece manter-se entre os desafios que constituem o campo educacional, em especial, na primeira etapa da Educação Básica.

\section{CONSIDERAÇÕES FINAIS}

Neste texto, abordamos a questão do planejamento e do trabalho das integrantes de equipes gestoras de Educação Infantil, considerando os contextos das Semes diante do desafio de garantir a todas as crianças

\footnotetext{
${ }^{29}$ Declaração expressa em questionário online, respondido voluntariamente. Respostas apuradas em 30 jan. 2015 pela pesquisadora.

${ }^{30}$ Declaração expressa em questionário online, respondido voluntariamente. Respostas apuradas em 30 jan. 2015 pela pesquisadora.

${ }^{31}$ Declaração expressa em questionário online, respondido voluntariamente. Respostas apuradas em 30 jan. 2015 pela pesquisadora.
} 
o direito à educação de qualidade. As questões referentes ao planejamento educacional, como parte do trabalho docente das equipes gestoras de Educação Infantil, não se situam apenas no campo das concepções, mas integram também as práticas e os processos de atuação desses sujeitos, compondo um conjunto articulado às conquistas e aos desafios vivenciados no cenário atual da Educação Infantil.

Cabe observar que as metas de universalização do atendimento educacional (BRASIL, 2014), especialmente o atendimento à faixa etária de quatro e cinco anos, até 2016, sinalizam a demanda de um planejamento por parte da gestão. Pesquisar como as equipes gestoras de Educação Infantil vêm se constituindo e se formando para o planejamento e o exercício de seu trabalho docente é essencial para compreendermos as organizações desse atendimento.

Indicamos que as participantes informam acerca do planejamento em associação à avaliação, evidenciando, inclusive, dificuldade para discernir as concepções e assinalando os esforços por encaminhar estratégias de ação que respondam efetivamente aos desafios emergentes no campo da Educação Infantil, em especial à pressão social pela expansão da oferta. Nesse quadro, reiteram-se preocupações com a atuação docente no reconhecimento dos direitos das crianças. Assim, as integrantes das equipes gestoras de Educação Infantil desenvolvem, planejam e avaliam em movimentos simultâneos, permanecendo dificuldades para efetivar políticas de planejamento que vivifiquem e atendam às necessidades da Educação Infantil. Nas pressões cotidianas, anunciam uma organização imediatista, balizada em experiências anteriores e, ainda que tenham posturas dinâmicas que demarquem a atuação, estas são insuficientes para atender aos desafios e demandas que se apresentam. Então, além de uma postura dinâmica, é necessário um planejamento coletivo, de modo que o processo educacional impulsione políticas efetivas que consolidem respostas consistentes aos desafios educacionais, sustentadas em uma gestão democrática.

Reconhecendo, nas vozes de nossas participantes, a diversidade como marca de nossa constituição como seres ativos, as concepções que elas enunciam nos movem a compreender os diferentes sentidos do planejamento e trabalho das equipes gestoras de Educação Infantil. A esse respeito, os enunciados evidenciam um planejamento concebido na atuação e uma busca, mesmo carecendo de ser fortalecida, por aproximações às concepções constantes em documentos oficiais e na legislação, em especial, as premissas das Dcneis (BRASIL, 2009).

Nesse sentido, podemos dizer que, assim como o campo da Educação Infantil vem se constituindo nesses últimos anos, juntamente estão se constituindo as equipes gestoras de Educação Infantil e, consequentemente, suas concepções, seu trabalho e as exigências de planejamento. A pesquisa revela os compromissos do trabalho das equipes gestoras em meio a desafios persistentes no campo da Educação Infantil, que indicam que seu fortalecimento não pode prescindir de investimentos em seus quadros profissionais.

\section{REFERÊNCIAS}

BAKHTIN, M. M. Estética da criação verbal: prefácio à edição francesa Tzvetan Todorov. Tradução do russo Paulo Bezerra. 6. ed. São Paulo: Martins Fontes, 2011.

BAKHTIN, M. M. Marxismo e filosofia da linguagem: problemas fundamentais do método sociológico na ciência da linguagem. 12. ed. São Paulo: Hucitec, 2009. https://doi. org/10.1590/2176-457336646

BAKHTIN, M. M. Questões de literatura e estética: a teoria do romance. 3. ed. São Paulo: Hucitec, 1993.

BRASIL. Constituição (1988). Constituição [da] República Federativa do Brasil, Brasília: Senado Federal, 1988. Disponível em: http://www.planalto.gov.br/ccivil_03/ constituicao/ConstituicaoCompilado.htm. Acesso em: 7 jun. 2013. https://doi.org/10.11606/d.2.2010.tde-13122010-160747

BRASIL. Decreto no 6.094, de 24 de abril de 2007. Dispõe sobre a implementação do Plano de Metas Compromisso Todos pela Educação, pela União Federal, em regime de colaboração com Municípios, Distrito Federal e Estados, e a participação das famílias e da comunidade, mediante programas e ações de assistência técnica e financeira, visando à mobilização social pela melhoria da qualidade da educação básica. Disponível em: http://www.planalto.gov.br/ccivil_03/_ ato2007-2010/2007/decreto/d6094.htm. Acesso em: 3 jan. 2016. https://doi.org/10.21573/vol32n012016.56381

BRASIL. Lei no 9.394, de 20 de dezembro de 1996. Estabelece as diretrizes e bases da educação nacional. Diário Oficial da União, Brasília, 23 dez. 1996. Disponível em: http://www.planalto.gov.br/CCIVIL 03/leis/L9394.htm. Acesso em: 4 abr. 2013. https://doi.org/10.11606/d.2.2017. tde-03102017-105747

BRASIL. Lei no 13.005, de 25 de junho de 2014. Aprova o Plano Nacional de Educação (PNE) e dá outras providências. Disponível em: http://www.planalto.gov.br/ccivil_03/ ato2011-2014/2014/lei/113005.htm. Acesso em: 27 jun. 2014.

BRASIL. Ministério da Educação. Secretaria de Educação Básica. Parâmetros nacionais de qualidade para a educação infantil. Brasília: DF, MEC, SEB, 2006. https://doi. org/10.20500/rce.v12i24.3658

BRASIL. Resolução CNE/CEB no 5, de 17 de dezembro de 2009. Fixa as Diretrizes Curriculares Nacionais para a Educação Infantil. Diário Oficial da União, Brasília, 18 dez. 2009. Disponível em: http://portal.mec.gov.br/conselhonacional-de-educacao/atos-normativos--sumulas-pareceres- 
e-resolucoes?id=12816. Acesso em: 4 mar. 2013. https://doi. org/10.21573/vol32n012016.65704

\section{CAMPOS, M. M. A gestão da educação infantil no Brasil.} São Paulo: Fundação Carlos Chagas, 2012.

CÔCO, V. Conquistas, avanços, desafios e disputas na política de educação infantil: transformação na docência. In: RANGEL, I. S.; NUNES, K. R.; CÔCO, V. Educação infantil: redes de conversações e produções de sentidos com crianças e adultos. Petrópolis: De Petrus, 2013. p. 180-199. https://doi.org/10.19177/prppge.v12e21201895-112

CÔCO, V. Trabalhador docente na educação infantil no Espírito Santo. In: FERREIRA, E. B.; OLIVEIRA, D. A.; VIEIRA, F. V. O trabalho docente na educação básica no Espírito Santo. Belo Horizonte: Fino Traço, 2012. p. 59-80. https://doi.org/10.1590/s1413-24782012000300007

FERNANDES, F. S.; GIMENES, N. A. S.; CAMPOS, M. M. Gestão educacional e educação infantil: formas de organização dos municípios para a implementação da política de educação infantil no Brasil. Revista Brasileira de Política e Administração na Educação, [S. l.], v. 29, n. 1, p. 61-78, jan./abr. 2013. https://doi.org/10.1590/s141324782002000100009

\section{INSTITUTO NACIONAL DE ESTUDOS E PESQUISAS EDUCACIONAIS ANÍSIO TEIXEIRA (INEP). Censo} Escolar. 2014. Brasília, DF: INEP, 2014. Disponível em: http://portal.inep.gov.br/resumos-tecnicos. Acesso em: 1 abr. 2015. https://doi.org/10.1163/1872-9037_afco_asc_1522

KRAMER, S. (Coord.). Formação de profissionais da educação infantil no Estado do Rio de Janeiro. Rio de Janeiro: Ravil, 2001. (Relatório de pesquisa). https://doi. org/10.5327/z1806-3144201600040005

KRAMER, S. et al. Nos relatos de professores, conquistas e ambiguidades da educação infantil. In: KRAMER, S. Profissionais da educação infantil: gestão e formação. São Paulo: Ática, 2005. p. 38-54. https://doi. org/10.11606/d.48.2013.tde-18122014-103728

KRAMER, S.; NUNES, M. F. Gestão pública, formação e identidade de profissionais de educação infantil. Caderno de Pesquisa, São Paulo, v. 37, n. 131, p. 423-453, maio/ ago. 2007. Disponível em: http://www.scielo.br/scielo. php?script=sci_arttext\&pid=S0100-15742007000200010\&ln $\mathrm{g}=\mathrm{en} \& \mathrm{nrm}=\mathrm{iso} \& \mathrm{tlng}=\mathrm{pt}$. Acesso em: 15 set. 2013. https://doi. org/10.1590/s0100-15742007000200010

MELLO, A. S.; PORTO, C. L. Concepções de formação em serviço: uma pesquisa com profissionais de Secretarias Municipais de Educação. In: REUNIÃO ANUAL DA ANPED, 26., out. 2003. Caxambu. Trabalho apresentado. Disponível em: http://26reuniao.anped.org.br/. Acesso em: 10 set. 2013. https://doi.org/10.18675/2177-580x.vol7.n1.p49-67

NUNES, M. F. R. Educação infantil no Estado do Rio de Janeiro: um estudo das estratégias municipais de atendimento. 2005, 250 f. Tese (Doutorado em Educação)
- Programa de Pós-Graduação em Educação: Universidade Federal do Rio de Janeiro, Rio de Janeiro, 2005. https://doi. org/10.17771/pucrio.acad.24856

VIEIRA, L. F.; OLIVEIRA, T. G. As condições do trabalho docente na educação infantil no Brasil: alguns resultados de pesquisa (2002-2012). Revista Educação em Questão, Natal, v. 46, n. 32, p. 131-154, maio/ago. 2013.

Recebido em: 16/4/2017.

Aprovado em: 14/3/2019.

Publicado em: 8/11/2019.

Endereço para correspondência:

Valdete Côco

Grupo de Pesquisa Formação e Atuação de Educadores - GRUFAE

Universidade Federal do Espírito Santo - UFES

Centro de Educação/Programa de Pós-Graduação em Educação Av. Fernando Ferrari, 514 - Campus Universitário - Goiabeiras 29075-910, Vitória, ES, Brasil

\section{Autoras:}

Marcela Lemos Leal Reis

Mestre em Educação pela Universidade Federal do Espírito Santo (UFES).

Pedagoga no Sistema Municipal de Ensino de Itapemirim/ES (SEME/ES). Integrante do Grupo de Pesquisa Formação e Atuação de Educadores (GRUFAE).

Orcid: https://orcid.org/0000-0002-6342-9475

E-mail: marcelallreis@gmail.com

VALDETE Côco

Doutora em Educação pela Universidade Federal Fluminense. Professora do Programa de Pós-Graduação em Educação (PPGE/UFES). Coordenadora do Grupo de Pesquisa Formação e Atuação de Educadores (GRUFAE).

Orcid: http://orcid.org/0000-0002-5027-1306

E-mail: valdetecoco@hotmail.com 